\title{
Reflexões sobre a confidencialidade como ética na prática profissional dos assistentes sociais
}

\author{
Reflections on confidentiality as ethics in the professional practice of \\ social workers
}

Maria Irene Carvalho ${ }^{1}$

Helena Teles ${ }^{2}$

Ana Paula Garcia ${ }^{3}$

\begin{abstract}
Resumo
A prática dos assistentes sociais tem-se confrontado com complexos problemas e dilemas éticos, sobretudo no que diz respeito ao princípio da confidencialidade. Sendo o Serviço Social uma profissão das relações sociais e humanas, a confidencialidade é um bem único e insubstituível que tem ganho destaque não só do ponto de vista normativo, mas do ponto de vista ético. Neste artigo, argumentamos que os profissionais asseguram a confidencialidade, promovendo os direitos das pessoas, mas enfrentam alguns desafios na sua prática profissional nem sempre fáceis de superar. Pretende-se refletir sobre o princípio da confidencialidade do ponto de vista normativo ético. Para atingir este objetivo, tomamos como referência as normas e os princípios éticos do código deontológico da Federação Internacional dos Assistentes Sociais, da Associação Internacional de Escolas dos Assistentes sociais e da associação de profissionais de Serviço Social e alguns exemplos práticos que foram revelados na revisão da literatura.
\end{abstract}

Palavras-chave: serviço social, confidencialidade, sigilo, profissão

\begin{abstract}
The practice of social workers has been faced with complex ethical problems and dilemmas, especially regarding the principle of confidentiality. As a social and human relations profession confidentiality is a unique and irreplaceable asset that has gained prominence not only from a normative point of view, but from an ethical point of view. In this article, we argue that professionals ensure confidentiality by promoting people's rights but face some challenges in their professional practice that are not always easy to overcome. It is intended to reflect on the principle of confidentiality from the ethical normative point of view. To achieve this goal, we take as reference the standards and ethical principles of the code of ethics of the International Federation of Social Workers, the International Association of Schools of Social Workers and the association of social work professionals and some practical examples that were revealed in the literature review.
\end{abstract}

Keywords: social work, confidentiality, secrecy, profession

\footnotetext{
${ }^{1}$ Professora Associada da Universidade de Lisboa, ISCSP/CAPP | E-mail: mcarvalho@iscsp.ulisboa.pt 2 Professora Auxiliar Convidada na Universidade de Lisboa, ISCSP/CAPP | E-mail: hteles@ iscsp.ulisboa.pt

3 Professora Auxiliar Convidada no Instituto de Serviço Social, ULHT | E-mail: anapaula.garcia@ulusofona.pt
} 


\section{Introdução}

O Serviço Social é uma prática profissional teórica e disciplinarmente orientada e eticamente informada (Shaw, Briar-Lawson, Orme e Ruckdeschel (ed) (2010). O Serviço Social centra-se na sociedade, em ações de promoção da coesão social e da justiça social, e na pessoa, em ações de promoção da emancipação, tendo em conta a dignidade humana (autonomia, liberdade), e os princípios dos direitos humanos (Carvalho, 2020). Seja no plano social ou individual, a confiança e a confidencialidade são a base da relação profissional.

Em Portugal, os profissionais que exercem a profissão do Serviço Social, são denominados de assistentes sociais. No código deontológico da profissão (APSS, 2019) estão definidos os atos profissionais. Estes integram um conjunto de ações que se articulam entre si tais como: atendimento, acolhimento, abertura de processo social e registos; a elaboração do diagnóstico social, perícias, pareceres, informações e relatórios sociais; o aconselhamento, orientação, prestação de informação e mediação social. Podem também conceber, planificar, implementar e avaliar projetos sociais de base comunitária. Estes atos são efetuados com respeito pela autonomia dos sujeitos, históricos, e das decisões que lhes dizem respeito.

Também gerem e administram equipamentos e serviços sociais e implementam, programas e políticas sociais. Para além dessas ações é ainda relevante destacar ações de assessoria e consultoria a órgãos da administração e gestão de entidades públicas, privadas e da economia social e de movimentos de cidadãos (APSS, 2019).

Neste conjunto de atos, estabelece-se uma relação profissional, onde a confidencialidade constitui um valor e um bem único insubstituível (Silva, 2020). A relação profissional implica o estabelecimento de um processo de confiança, que deve ser recíproco: de alguém que confia e de alguém que é confiável. Isto é, alguém, que é o repositório da informação vinculada e que tem a responsabilidade de manter essa informação sobre sigilo. Nesta relação, as pessoas e entidades depositam nos assistentes sociais conhecimento sobre si e as suas circunstâncias, e reconhecem no profissional a confiança necessária para promover e assegurar os seus direitos.

A confidencialidade é um elemento-chave da relação profissional, que se estabelece entre um assistente social e os «constituintes» da intervenção: pessoas, comunidades e sociedade. Nesta relação, o profissional tem acesso a dados sensíveis, a hábitos e comportamentos, que tem de proteger. Estes dados são propriedade dos 
intervenientes da intervenção, das pessoas e organizações, e não podem ser partilhados sem o consentimento, livre e informado dos mesmos. E mesmo com o consentimento livre e informado, o assistente social tem o dever de sigilo.

Apesar dos dados pessoais estarem protegidos por lei, e dos profissionais terem o dever de sigilo, verifica-se atualmente uma certa banalização da informação, feita tanto nas redes sociais como nos média e sobre a qual é necessário considerar. Esta banalização é mais frequente nos grupos de pessoas vulneráveis com as quais os profissionais de Serviço Social exercem a profissão. Estas pessoas vêm frequentemente a sua vida exposta na comunicação social, onde o sensacionalismo impera e naturaliza e discrimina a vida destas pessoas vulneráveis (Sampaio \& Rodrigues, 2014). É frequente assistirmos a programas onde pessoas e famílias expõem as suas vidas e as suas vulnerabilidades publicamente. Muitas destas pessoas já suportam uma maior interferência e intervenção do poder público do que outros grupos da população e veem, desta forma, a sua condição ser banalizada na sociedade.

A relação profissional/utente, também, passou de uma relação a dois (profissional/utentes) para ser uma relação de múltiplas relações (múltiplos profissionais/utente). Esta especificidade exige uma abordagem multidisciplinar onde invariavelmente entram outros profissionais (Silva, 2020). A sociedade global requer um trabalho desenvolvido em rede, com metodologias colaborativas e partilha de dados por várias entidades e profissionais. A especialização complexifica-se no contexto da deste tipo de sociedade, em rede, onde a responsabilidade das organizações e dos profissionais é assumida como resposta à sofisticação dos problemas.

Tendo em conta este enquadramento, questionamos neste artigo, de que modo o assistente social pode assegurar a confidencialidade, mantendo os direitos das pessoas, a sua autonomia e dignidade? Que desafios os profissionais enfrentam na prática profissional na defesa da confidencialidade?

Pretendemos refletir sobre o princípio da confidencialidade, não só do ponto de vista normativo, mas do ponto de vista ético e fazemos uma reflexão sobre o sigilo e a confidencialidade, tendo como referência as normas e princípios éticos da Federação Assistentes Sociais e do código deontológico dos assistentes sociais em Portugal. Trazemos ao debate alguns dos aspetos essenciais para um melhor entendimento do processo de partilha de informação e da confidencialidade no âmbito da intervenção do 
Serviço Social, refletimos com exemplos de casos concretos e ponderamos sobre os princípios da confidencialidade e sobre os desafios para a profissão.

\section{Informação pessoal privada, sigilo, confidencialidade e consentimento informado}

A informação pessoal privada, está associada ao direito à privacidade e está intimamente relacionada com o direito dos indivíduos sobre as suas informações pessoais. Não envolve só as informações que o próprio tenha transmitido a terceiros, expressa ou implicitamente, esperando que elas as mantenham em sigilo. $\mathrm{O}$ direito à privacidade aplica-se a todas as informações pessoais (McHale, 2003). Neste sentido a Convenção Europeia dos Direitos do Homem (1950), consagra o direito (Artigo $8^{\circ}$ ) ao respeito pela vida privada e familiar, a saber:

1. Qualquer pessoa tem direito ao respeito da sua vida privada e familiar, do seu domicílio e da sua correspondência.

2. Não pode haver ingerência da autoridade pública no exercício deste direito senão quando esta ingerência estiver prevista na lei e constituir uma providência que, numa sociedade democrática, seja necessária para a segurança nacional, para a segurança pública, para o bem-estar económico do país, a defesa da ordem e a prevenção das infrações penais, a proteção da saúde ou da moral, ou a proteção dos direitos e das liberdades de terceiros (Conselho da Europa, 1950, p. 11).

Do ponto de vista jurídico, os dados que as pessoas autorizam a que os profissionais tenham acesso, são objeto de legislação de proteção de dados pelo Regulamento Geral sobre a Proteção de Dados (RGPD) (UE) 2016/679 do Parlamento e do Conselho, de 27 de abril de 2016, e do Estado português pelas Lei n. ${ }^{\circ}$ 58/2019 e n. $^{\text {o }}$ 59/20195 , ambas de 8 de agosto.

O Regulamento (UE) 2016/679 determina as regras sobre a proteção das pessoas singulares no que concerne ao tratamento dos seus dados pessoais, conforme disposto no art. $1 .^{\circ}$ do mesmo. O qual define dados pessoais, no n. ${ }^{\circ} 1$, do art. $4 .^{\circ}$, como todas as

\footnotetext{
${ }^{4}$ Assegura a execução, na ordem jurídica nacional, do Regulamento (UE) 2016/679 do Parlamento e do Conselho, de 27 de abril de 2016.

5 Aprova as regras relativas ao tratamento de dados pessoais para efeitos de prevenção, deteção, investigação ou repressão de infrações penais ou de execução de sanções penais, transpondo a Diretiva (UE) 2016/680 do Parlamento Europeu e do Conselho, de 27 de abril de 2016.
} 
informações que individualmente ou conjuntamente tornam o titular dos dados como uma pessoa identificada ou identificável.

No que respeita ao enquadramento legislativo português, destaca-se que o tratamento dos dados pessoais que revelem a origem racial ou étnica, as opiniões políticas, as convicções religiosas ou filosóficas ou a filiação sindical, bem como dos dados genéticos, dos dados biométricos destinados a identificar uma pessoa singular de forma inequívoca, dos dados relativos à saúde ou dos dados relativos à vida sexual ou à orientação sexual, só pode ser efetuado se for estritamente necessário, se estiver sujeito a garantias adequadas de proteção dos direitos e liberdades do titular dos dados, e se: a) for autorizado por lei; b) se destinar a proteger os interesses vitais do titular dos dados ou de outra pessoa singular; ou c) estiver relacionado com dados manifestamente tornados públicos pelo titular dos dados" (Lei n. ${ }^{\circ}$ 59/2019, p. 44).

O sigilo profissional é considerado uma conceção central no exercício de atividades profissionais, está presente em muitas áreas profissionais e inspira confiança nos domínios onde deve ser respeitado e tido em consideração. As principais profissões onde o sigilo profissional pode ser considerado fundamental incluem as que afetam a saúde e o bem-estar, como médicos, assistentes sociais, enfermeiros, mas também polícias, professores, entre outros, porque "são confidentes necessários" (Meersseman, 2019). As pessoas que exercem estas profissões não podem, por norma, divulgar qualquer informação que lhes seja transmitida no exercício das suas funções. Para Crête \& Dufour (2016) o sigilo profissional pode ser justificado por razões históricas ou éticas, ou para manter a dignidade de uma profissão, no sentido de promover a lealdade do profissional para com o seu cliente.

O respeito pelo sigilo profissional no caso dos assistentes sociais pode ser considerado como uma "necessidade social". Uma pessoa que solicita ajuda ao assistente social deve ter a garantia da total confiança no profissional. A confidencialidade, relativamente aos elementos que o assistente social recolhe, é essencial para que se estabeleça uma relação de confiança e para que o utente possa contar a sua história de vida e a sua situação com segurança.

Se não existirem garantias de sigilo profissional a pessoa, o utente, pode nunca revelar dados que são fundamentais para a resolução dos seus problemas. Além do interesse individual que todos possam ter em respeitar o sigilo profissional, é também 
do interesse da própria sociedade que haja lugares onde todos possam confiar e encontrar ajuda sem que o que for dito se volte contra a própria pessoa.

O sigilo refere-se a algo que precisa ser protegido e remete para o que não pode ou não deve ser revelado, sendo necessário, discrição e reserva (Sampaio e Rodrigues, 2014. O sigilo profissional refere-se a uma informação que deve ser preservada, pois implica uma relação entre privacidade e divulgação. Toda a informação deve ser objeto de sigilo constituindo-se este como um princípio e uma norma que está inserida dentro de um projeto com valores de liberdade, do não autoritarismo e do respeito (Sampaio e Rodrigues, 2014).

Implica a preservação do direito que as pessoas têm ao sigilo, para as preservar e proteger, viabilizando assim direitos, mas também protege a autonomia do profissional (Sampaio e Rodrigues, 2014). O dever profissional estabelece-se desde, «a se ater ao estritamente necessário ao cumprimento de seu trabalho, a não informar a matéria sigilosa» (Sampaio \& Rodrigues, 2014, p. 86). Só através da justiça esses dados podem ser divulgados, e mesmo nestes casos excecionais, em que os dados tenham de ser divulgados, os mesmos têm de ter em conta a finalidade da ação, mantendo a reserva da informação recebida.

Destaca-se que a violação do dever de sigilo, tem consequências, ou seja, o profissional que "sem justa causa e sem o devido consentimento, revelar ou divulgar, no todo ou em parte, dados pessoais tratados ao abrigo da presente lei, é punido com pena de prisão até 2 anos ou com pena de multa até 240 dias" (Lei n. ${ }^{\circ}$ 59/2019, p. 65).

Associado ao sigilo está a confidencialidade. Esta é a base de uma relação de ajuda e deve estar presente a partir do momento que uma pessoa confia algo a outra, sendo o profissional que assegura e garante o sigilo e a confidencialidade daquilo que é confiado na relação com o paciente ou utente. Para Meersseman (2019) o sigilo é a base de qualquer sociedade democrática para preservar esses espaços de confidencialidade enquanto valor essencial em qualquer relacionamento de ajuda.

O princípio da confidencialidade pressupõe reconhecer o sigilo como um direito das pessoas ao fazer uso de informação sobre os dados pessoais apenas sob consentimento informado, esclarecido e livre, no cumprimento da regulamentação sobre a proteção de dados e das orientações deontológicas para a profissão. É também relevante informar as pessoas, as organizações e outros profissionais sobre as condições e os limites à confidencialidade profissional a que está sujeito (APSS, 2019, pp. 11-12). 
O princípio da confidencialidade tem subjacente, por um lado, a tomada de decisões práticas que fortaleçam o direito à privacidade e à confidencialidade de qualquer pessoa, e por outro lado, a manutenção da confidencialidade (Dolgoff, Loewenberg, \& Harrington, 2009).

Sempre que uma pessoa dá informações sobre si próprio ou outros é na expectativa que as mesmas sejam mantidas confidenciais e que não sejam divulgadas a outras pessoas, estamos perante a obrigação de confiança de reserva de todo e qualquer tipo de informação. A pessoa que revela informações, nesta expectativa, vincula ao destinatário das mesmas a obrigação de confidencialidade.

A confidencialidade está associada ao consentimento informado, livre e esclarecido e refere-se à participação de pessoas capazes de dar consentimento informado para serem participantes em estudos ou em intervenções profissionais.

Primeiro, as pessoas têm de ser capazes de consentir.

Segundo, cada potencial sujeito tem de ser informado adequadamente das finalidades, métodos, fontes de financiamento e possíveis conflitos de interesse, ligações institucionais do investigador, benefícios expectáveis, potenciais riscos do estudo e incómodos que lhe possam estar associados, ajudas após o estudo, bem como outros aspetos relevantes do estudo.

Terceiro, o potencial participante tem de ser informado do direito a recusar-se a participar ou de, em qualquer altura, revogar o consentimento de participar sem represálias.

Quarto, o consentimento livre e informado do potencial participante, deve ser preferencialmente por escrito. Se o consentimento não pode ser feito por escrito, o consentimento verbal tem de ser formalmente documentado e testemunhado. Quando as pessoas são incapazes física ou mentalmente de dar consentimento, este deve ser dado pelo seu representante legal (Resolução da Assembleia da República n. ${ }^{\circ}$ 1/2001 e Declaração de Helsínquia de 2013).

\section{Referencial de conduta ética - Código Deontológico}

Na Lei n. ${ }^{\circ}$ 121/2019 que cria a ordem dos Assistentes Sociais é assumido que estes profissionais têm a obrigação de assegurar a manutenção da privacidade de toda a informação a respeito do destinatário dos serviços (...) recolhem e registam apenas a informação estritamente necessária sobre o destinatário dos serviços, de acordo com os 
objetivos em causa. O arquivo, manipulação, manutenção e destruição de registos, relatórios ou quaisquer outros documentos acerca do destinatário dos serviços são efetuados de forma a assegurar a privacidade da informação» (Lei n. ${ }^{\circ}$ 121/2019, de 25 de setembro de 2019, art. $\left.{ }^{\circ} 109\right)$.

Por outro lado, assume que pode haver quebra de confidencialidade quando existir uma situação de perigo para o destinatário dos serviços ou para terceiros, que possa ameaçar de uma forma grave a integridade física ou psíquica, perigo de dano significativo para o envolvido e/ou para terceiros. Também é importante revelar que em situações de articulação interdisciplinar e institucional, os assistentes sociais podem partilhar informação considerada confidencial sobre o destinatário dos serviços» (Lei n. ${ }^{\circ}$ 121/2019, p. 35).

O documento, alude ainda que «a não manutenção da privacidade pode justificarse sempre que se considere existir uma situação de perigo para o destinatário dos serviços e/ou para terceiros, que possa ameaçar de uma forma grave a integridade física ou psíquica, perigo de dano significativo, ou qualquer forma de maus-tratos a indivíduos, menores ou adultos, particularmente indefesos, em razão de idade, deficiência, doença ou outras condições de vulnerabilidade física, psíquica ou social. Os assistentes sociais que integrem equipas de trabalho, em situações de articulação interdisciplinar e institucional, podem partilhar informação considerada confidencial sobre o destinatário dos serviços» (Lei n. ${ }^{\circ}$ 121/2019, de 25 de setembro de 2019, art. ${ }^{\circ}$ 109).

Tanto a privacidade como a confidencialidade, são integradas no código deontológico dos assistentes sociais (APSS, 2019), pois é este que assegura o sigilo e a confidencialidade do exercício profissional.

No caso dos assistentes sociais, os códigos de ética ou deontológicos têm sido uma preocupação desde o início da profissão. Esta inquietação tem sido consistente desde as práticas de Mary Richmond (Bulgaru, 2013; Dolgoff, Harrington, Loewenberg, 2012). Tais preocupações materializam-se em 1920 com a publicação do "projeto experimental de código de ética para assistentes sociais" (Agnew, 2004). Tal facto é revelador das preocupações para determinar os princípios e valores presentes na intervenção social. Contudo é partir da década de sessenta e setenta que os códigos deontológicos se começam a generalizar nas associações de profissionais de vários países (por exemplo o dos EUA) (Reamer, 2012). 
A federação dos profissionais de Serviço Social publicou em 1994 um código de ética para os profissionais de Serviço Social. Este código tem sido objeto de várias reformulações, datando a última de 2018. Neste código de ética, da Federação Internacional dos Assistentes Sociais, tanto a privacidade como a confidencialidade, ocupam um lugar de destaque. Assume que os assistentes sociais respeitam e trabalham de acordo com os direitos das pessoas a confidencialidade e a privacidade, a menos que haja risco de dano a si mesmo ou a outras pessoas ou outras restrições estatutárias. Os assistentes sociais têm o dever de informar as pessoas com quem se envolvem sobre os limites à confidencialidade (IFSW, 2018).

No código deontológico dos assistentes sociais em Portugal (APSS, 2019) a confidencialidade tem também um lugar de relevo. Nele é assumido que os assistentes sociais têm «a obrigação no desempenho profissional de reconhecer o sigilo como um direito das pessoas; estabelecer uma relação profissional fundada na confiança e na garantia da privacidade e do sigilo sobre informações pessoais partilhadas; fazer uso de informação e dados pessoais apenas sob consentimento informado, esclarecido e livre, no cumprimento da regulamentação sobre proteção de dados em vigor em Portugal e orientações internacionais para a profissão; abdicar do princípio da confidencialidade sempre que a pessoa não possa ser responsabilizada ou em que outros possam ser colocados em risco; informar as pessoas, organizações e outros profissionais sobre as condições e os limites à confidencialidade profissional a que está sujeito» (p.11).

\section{A profissão do Serviço Social e o princípio da confidencialidade}

A confidencialidade do ponto de vista ético tem sido analisada por autores do Serviço Social, quer nacionais quer internacionais, mas nem sempre com o merecido destaque. Como argumentamos, a confidencialidade, não se limita a um preceito legal/jurídico, mas é uma questão ética, como já referimos. A confidencialidade em Serviço Social é entendida como um princípio fundamental na relação entre o Assistente Social e a pessoa, o destinatário da intervenção (Collingridge, Miller \& Bowles, 2008), pois leva à construção de uma relação de confiança entre as duas partes envolvidas no processo de intervenção social.

A confidencialidade é entendida, também, como um elemento determinante para o estabelecimento de confiança na relação do profissional com os destinatários da 
intervenção (Frunza, 2011). A relação profissional implica decisões que tem de ser balizadas pelo princípio da confidencialidade.

Sampaio \& Rodrigues (2014) consideram que qualquer «decisão ética resulta de uma deliberação, de uma escolha consciente diante da pluralidade de elementos que envolvem determinada questão. Sendo que qualquer decisão terá implicações para si mesmo, para o utilizador do serviço, para a instituição e para o conjunto da sociedade. Por isso é preciso considerar a opinião da pessoa, e ponderar se a informação tratada é ou não confidencial, seu objetivo profissional, para que serve a partilha de tal informação, e com quem compartilhá-la; e, ainda, o que é melhor para garantir determinado direito» (p. 91).

Os assistentes sociais gerem a informação que lhes é transmitida pelas pessoas em contexto de atendimento social. Esta informação é especialmente sensível quando se verifica a existência de um trabalho de articulação interpares que requer partilha de informação e onde é necessário para assegurar os direitos das pessoas (Almeida, 2017). A autora assume que a falta de reflexão sobre o tema, tem conduzido a dúvidas e interrogações nos profissionais sobre o que se deve ou não partilhar.

Por exemplo Day e all (2013) chamam a atenção para processos profissionais onde existe a necessidade de partilhar informação com várias organizações que tratam do caso da mesma pessoa. A regra geral da confidencialidade assume que a partilha de informação tem de ser autorizada pelos próprios. Contudo no caso das crianças, que se encontram no sistema de proteção, colocam-se várias questões, pois a maioria destas ainda não se encontra em condições de dar o seu consentimento. Assim compete ao profissional assumir a confidencialidade como uma consequência do compromisso com a autodeterminação e com o superior interesse das crianças.

Banks e outros autores (2020), também chamam a atenção para o exercício profissional da ética em contexto de pandemia da Covid-19. Os autores, refletiram sobre estes temas e consideraram pertinente a necessidade de criar e manter relacionamentos de confiança, honestidade e empatia via telefone ou internet com o devido respeito à privacidade e confidencialidade, em tempo de pandemia. Neste contexto uma das questões apontada é a dificuldade de manter a privacidade dos utentes sobretudo quando estes estão confinados em casa e outros elementos da família, podem ouvir conversas pessoais sensíveis. Também nos casos em que existem potenciais casos em que vítimas convivem com o agressor (Banks et. al. (2020). Outras das questões evidenciadas pelos 
autores é o comprometimento do contacto pessoal com os utilizadores dos serviços, quando temos de usar máscara, pois esta impede não só a observação das expressões do utente como também prejudica a comunicação de informações necessárias às decisões profissionais.

O uso de ferramentas digitais para e durante o exercício da prática profissional é uma questão também debatida por Halabuzar (2014) e Reamer (2017). O recurso às novas tecnologias tais como o uso maciço dos contactos virtuais telefónicos e online, também nos desafia eticamente sobretudo no que diz respeito à validade da informação, à privacidade, à confidencialidade e aos julgamentos profissionais.

Reamer (2017) identifica um conjunto de questões muito pertinentes no que diz respeito à confidencialidade das quais se salientam:

i) as recentes evoluções das questões éticas do Serviço Social prendem-se com o uso das tecnologias por parte dos assistentes sociais com o fim de transmitir informação e comunicar com os utentes;

ii) há um número cada vez mais significativo de assistentes sociais a recorrer inteira ou parcialmente às várias formas de comunicação digital para “educar" e servir as necessidades das populações com quem trabalham;

iii) o Serviço Social já não está limitado ao trabalho de gabinete e às visitas domiciliárias e interações diretas com as pessoas. O autor dá o exemplo de assistentes sociais que recorrem ao uso de vídeo para sessões de aconselhamento via chat de e-mail, intervenções de aconselhamento pela internet; aplicações de smartphone, entre outras;

iv) alguns assistentes sociais estão a usar a tecnologia como um complemento às técnicas tradicionais, embora haja casos em que o assistente social recorre inteiramente à tecnologia na sua intervenção e isso cria uma distância formal com o utente;

v) muitos assistentes sociais têm por base uma rotina profissional que implica o uso de redes sociais e de mensagens de telefone;

vi) outros desafios éticos atuais da profissão relacionam-se com a privacidade, confidencialidade, consentimento informado, conflitos de interesse, documentação, abandono de utentes, profissionalismo, entre outros;

vii) os assistentes sociais devem ter presente a legislação e respeitar a confidencialidade dos dados dos utentes e protegê-los de terceiros. Devem usar o 
seu sentido de julgamento corretamente antes de pesquisarem informações pessoais dos utentes através do Facebook, por exemplo, ou de outra rede social. Este caso só pode ocorrer havendo uma situação de emergência ou se o utente der consentimento informado para que se aceda à sua informação;

viii) a comunicação digital introduziu novos desafios no que diz respeito aos limites entre assistentes sociais e utente.

Por outro lado, Halabuzar (2014) chama a atenção para a informação que é divulgada em blogs, no Facebook e outras redes semelhantes, sobre a vida pessoal dos profissionais e quando muitas vezes são discutidas questões online sobre a intervenção profissional. A partilha dessas informações deve evitar-se sobretudo, as que são partilhadas online (via e-mail, mensagens de texto, e publicações nas redes sociais). Para Reamer (2017) deve estabelecer-se um conjunto de linhas que limitem as interações com utentes online e outros meios eletrónicos, durante o dia/noite, fins-desemana e feriados (Reamer, 2017).

Halabuzar (2014) refere-se também ao facto de muitos profissionais terem redes sociais próprias, que integram supostos "amigos", que podem bem ser seus clientes. Por outro lado, os profissionais também podem ter acesso a informação pessoal dos utentes que é vinculada por esta via. É de extrema relevância que se separe a vida pessoal da profissional, mantendo o dever de respeito pelas informações vinculadas que o princípio da confidencialidade exige.

\section{Limites à confidencialidade - questões práticas}

$\mathrm{Na}$ prática dos assistentes sociais há um conjunto de questões que podem ser objeto de reflexão no que diz respeito à confidencialidade. Desde logo é importante saber, quando se pode partilhar informação e que informação deve ser partilhada? Apesar dos dados pessoais serem objeto de sigilo, isso não quer dizer que não se possa partilhar informação. Numa relação profissional a informação a partilhar, tem de ser do conhecimento da pessoa visada e ser adequada à finalidade que a mesma se destina. Por exemplo uma pessoa para ter acesso a um benefício social, como o complemento de dependência tem de revelar em documentos próprio, da sua idade, estado civil, morada e incluir um atestado médico onde está descrito a potencial situação de saúde da qual decorre a dependência. Estes dados são essenciais para que a pessoa tenha acesso a este benefício social. 
Que informação se deve partilhar com outros profissionais e com outras entidades? Num contexto interserviços e multiprofissional os profissionais, que têm de ter conhecimento de informação relevante da vida dos utilizadores dos serviços, e têm o dever ético de usar essa informação tendo em conta o seu superior interesse. No âmbito profissional, os profissionais analisam os dados e as informações recolhidas sobre a pessoa interpretando-os científica, técnica e eticamente. Esta informação que é transmitida a outras entidades e outros profissionais, deve ser efetuada com o consentimento da pessoa com o objetivo de zelar pelos seus interesses no que diz respeito ao acesso a direitos.

Quais as responsabilidades das organizações na proteção dos dados pessoais dos cidadãos? A confidencialidade «é a base ética para a partilha de dados pessoais cabendo ao profissional manter essa confiança na relação de ajuda» (ARSLVT, 2014, p.2). A organização ou instituição onde o profissional exerce a profissão também tem o dever de sigilo, armazenando, guardando, não divulgando os dados e não permitindo o acesso a terceiros aos mesmos (ARSLVT, 2014). Estas entidades têm de armazenar os dados e ter bases de dados seguras, não divulgar a ninguém, sem o consentimento dos titulares dos mesmos, exceto em casos em que o tribunal ordene a sua divulgação. Mas mesmo neste caso a informação a divulgar tem de ser ponderada tendo em conta a situação em causa.

Algumas organizações sociais e de saúde onde os profissionais exercem a profissão desenvolveram códigos de ética onde a confidencialidade é tratada como um dos princípios mais relevantes. Por exemplo no caso dos profissionais que exercem função em organismos do ministério da saúde, o sigilo profissional é uma matéria que está destacada no ponto 9 do código de conduta das entidades de saúde (Diário da república, 2014). Nele é referido que todos «os colaboradores devem guardar sigilo relativamente a dados pessoais e outra informação direta ou indireta relacionada com a saúde dos cidadãos» (p.18778-12). Para as profissões com códigos deontológicos, estes devem assegurar a segurança dos dados recolhidos e os profissionais devem seguir as regras neles constantes, mantendo o dever do sigilo mesmo após a cessão de funções (ARSLVT, 2014). A confidencialidade ganha destaque enquanto norma e enquanto princípio ético.

Quando o dever da confidencialidade colide com o dever de informar? Os assistentes sociais têm a obrigação de proteger e informar sempre que existem situações 
sociais que possam colocar em risco o estado de bem-estar da população, a saúde pública ou a própria condição do beneficiário. Por exemplo, o surgimento do HIV tornou imprescindível a mobilização da sociedade para preocupações com a privacidade e confidencialidade e para a necessidade de refletir acerca de aspetos éticos. Fez surgir aspetos bastante delicados, levando a reflexões em que era necessário ponderar os direitos e as necessidades dos indivíduos e do bem público.

$\mathrm{O}$ assistente social que trabalha com pessoas infetadas pelo HIV enfrenta um dilema ético da obrigação de informar versus o da confidencialidade, quando deve tomar a decisão de informar os familiares da pessoa infetada, mas também pessoas de sua rede social que podem estar vulneráveis à infeção pelo HIV, caso o beneficiário decida ter contato sexual desprotegido, sem previamente informá-lo de sua condição médica. Se violar o sigilo, o cliente enfrenta grandes riscos de discriminação e exclusão social, devido aos preconceitos em determinados ambientes sociais e culturais em relação aos portadores do HIV.

Como cumprir o dever da confidencialidade e proteger as vítimas? Os assistentes sociais têm acesso a dados confidenciais sobre o comportamento abusivo de um dos pais para com o seu filho(a). A pergunta legítima que o assistente social se faz é: quando ele deve sinalizar o caso ao sistema de proteção da criança retirando-a da família e quando alertar as autoridades para o mau trato de crianças, especialmente quando não há evidências de violência além dos testemunhos das crianças? Em Portugal, há um número de telefone especial que as crianças podem usar para relatar situações de violência na família. A simples obrigação de proteger as vítimas requer o estabelecimento de certas investigações e a tomada de medidas que podem levar à institucionalização das crianças.

O sigilo pode ser quebrado? Os profissionais só podem quebrar a confidencialidade - quando há dano para a pessoa e para as pessoas envolvidas ou quando o tribunal necessita de informação, mas mesmo assim é necessário ponderar eticamente que informação é pertinente revelar. A quebra do sigilo é sempre relativa a casos concretos/excecionais e que devem ser muito bem analisados e avaliados, no entanto, por vezes é mesmo necessária. A quebra de sigilo profissional está contemplada nos códigos de ética profissional e decorre de necessidades da prática do assistente. Ou seja, as resoluções de algumas situações exigem a colaboração e coordenação de e entre vários profissionais e serviços. A partilha de informação sobre o utente por parte do 
assistente social é assim necessária para que cumpra a sua missão e, quando isso acontece não é considerada quebra de sigilo profissional.

Por vezes, há situações de pessoas que estão em momentos de crise e que no momento do atendimento telefónico expressam a manifesta vontade de suicídio. Nestes casos tenta-se que a pessoa nos indique a sua localização exata, articulando com a Polícia Criminal para que intervenha no momento. Outra das situações em que por vezes se quebra o sigilo é com os casos de Violência Doméstica, em que a denúncia lhes dá todos os dados do/a lesado/a, mas depois não facilita a articulação com a vítima, ou a própria vítima não aceita essa agilização.

Contudo há claramente um risco aumentado ou extremo, implícito na situação que foi exposta, e por ser um crime público e haver um manifesto risco aumentado implícito, pode-se em última instância, recorrer à denúncia e exposição da ocorrência ao MP solicitando a intervenção dos mesmos.

Um utente é atendido pela assistente social do RSI. Durante o atendimento assume que tem um trajeto associado ao consumo de drogas e de álcool e que esteve em abstinência durante algum tempo, mas ultimamente consumia canábis, porque se sentia descompensado. Tinha também deixado de ir às consultas de psiquiatria. E, agora porque tinha voltado a consumir não tinha à vontade para falar do assunto à assistente social da saúde mental, por quem era acompanhado anteriormente. A assistente social do RSI, após ter o consentimento do utente, entrou em contacto com a colega e abordou com ela estes novos consumos do utente.

\section{Conclusão}

A confidencialidade e o sigilo profissional são princípios éticos e constituem-se a condição fundamental para que uma pessoa possa confiar e ter garantia de confiança para dar elementos íntimos da sua situação ou da sua história. O sigilo profissional, abrange toda a informação, desde o simples fato de uma pessoa se apresentar a um profissional e ou recusar dados da sua identidade. Isso requer por parte do profissional garantir o enquadramento e as condições para assegurar o respeito por toda a informação que se confia na relação.

Neste artigo, a confidencialidade foi discutida do ponto de vista ético como um dever de guardar todas as informações que se relacionam com a privacidade de uma pessoa, inclui a proteção de informações privadas e íntimas e é um direito de quem 
transmite dados de natureza pessoal. Contudo, como demonstramos ao longo deste texto há situações em que pode haver a necessidade de se quebrar a confidencialidade ao revelar-se informação que foi fornecida pessoalmente e em confiança.

Nos códigos de ética e deontologia profissional a quebra de confidencialidade é permitida, quando dela resulte um benefício real e se tiverem esgotado todas as outras possibilidades. Este princípio deontológico está relacionado/associado ao sigilo ou segredo profissional.

A confidencialidade tem uma estreita relação com a noção de confiança que se estabelece entre o assistente social e a pessoa que procura o seu apoio. Requer desta forma que se crie um clima de segurança, para a partilha de algo íntimo, sendo essa segurança uma condição essencial para que tal aconteça. A ética pode considerar-se uma ferramenta que torna possível encontrar soluções para o dilema entre o sigilo profissional e proteção da pessoa em situação de vulnerabilidade.

O segredo profissional é algo complexo pois não é fácil aos profissionais, no seu quotidiano, determinarem com objetividade o que podem ou não revelar e quando o fazer. Na prática, a aplicação desta noção remete para a consciência e valores do próprio profissional, exigindo-se que este tenha sempre presente o seu código de ética e deontologia.

Os padrões que predominam na sociedade atual, dominada pelas tecnologias da informação e pela exposição desregrada da vida pessoal, comprometem o respeito pela privacidade dos indivíduos e famílias, que serve de base ao sigilo profissional, estando assim esta dimensão em declínio. A alteração de valores verificada nas últimas décadas coloca muitas questões sobre o tema abordado, contudo fica a certeza de que a manutenção do sigilo profissional é fundamental na intervenção dos assistentes sociais e uma condição sine qua non para que não se ponha a causa a relação de confiança entre o profissional e o destinatário da sua ação.

\section{Referências bibliográficas}

Almeida, N.T. S. (2017). A confidencialidade na prática profissional d@ assistente social: do princípio à operacionalização [Tese de Mestrado, ISCTE]. http://hdl.handle.net/10071/15126

APSS (2019). Código deontológico dos Assistentes Sociais em Portugal. APSS.

ARSLVT (2014). Comissão de ética para a saúde, Parecer, 3/AS/CES/2014. ARSLVT. 

Editora.

Banks, S. (2008). Ética prática para as profissões do trabalho social. Porto

Banks, S. (2014). Ethics. In Ian Fergunson and Michael Lavalette (eds.). Critical and radical debate in social work. Policy Press.

Banks, S., Cai, T., de Jonge, E., Shears, J., Shum, M., Sobočan, A. M., Strom, K., Truell, R., Úriz, M. J., Weinberg, M. (2020). Ethical challenges for social workers during Covid-19: A global perspective. International Federation of Social Workers.

Barroco, L. (2005). Ética e Serviço Social, Fundamentos ontológicos. Cortez.

Beckett, C. Maynard, A. Jordan, P. (2016). Values \& ethics in SW. Sage.

Brito, J. H.S. (2016). Ética Geral e Éticas Aplicadas. In Neves, M.C.P (Coord). Dos fundamentos às práticas. Ediçoes70.

Carvalho, M. I. (2016). Ética aplicada ao Serviço Social. Dilemas e Práticas. Pactor.

Carvalho, M. I. (2020). Ser Assistente Social, retratos da profissão. Pactor.

Carvalho, A., \& Baptista, I. (2008). Ética e formação profissional: problemas antropológicas e dilemas éticos na intevenção socioeducativa. Em S. Banks, \& K. Nøhr, Ética Prática para as Profissões do Trabalho Social (19-32). Porto Editora.

Collingridge, M., Miller, S., \& Bowles, W. (2008). Privacy and confidentiality. In social work. Australian Social Work, 54(2), 3-13. https://doi.org/10.1080/03124070108414319

Conselho da Europa, (1950). Convenção Europeia dos Direitos do Homem. Estrasburgo, Conselho da Europa.

Crête, R. \& Dufour, M.H. (2016). L'exploitation des personnes aînées : pour un élargissement des dérogations au secret professionnel. Revue générale de droit, 46, 397-462. https://doi.org/10.7202/1036167ar

Day, A.; Edwards, H..; Pickover, S. \& Leever, M. (2013). When Does Confidentiality Become an Impediment Rather Than a Pathway To Meeting the Educational Needs of Students in the Foster Care System?. Journal of Social Work Values and Ethics, Volume 10, Number 2, 36-47.

Diário da Républica (2014). Enquadramento de princípios orientadores. Código de conduta ética dos serviços e organismos do ministério da saúde. Publicado no Diário da República, $2^{\text {a }}$ série, no 138, 21 de julho, pp. 18778- (11-13).

Diário da Républica (2019). Aprova as regras relativas ao tratamento de dados pessoais para efeitos de prevenção, deteção, investigação ou repressão de infrações penais ou de execução de sanções penais, transpondo a Diretiva (UE) 2016/680 do Parlamento Europeu e do Conselho, de 27 de abril de 2016, lei ${ }^{\circ} 59$, publicada no diário da república, $1^{\mathrm{a}}$ série, $\mathrm{n}^{\mathrm{o}} 151$, p. 41-68.

Diário da Républica (2019). Assegura a execução, na ordem jurídica nacional, do Regulamento (UE) 2016/679 do Parlamento e do Conselho, de 27 de abril de 2016, relativo à proteção das pessoas singulares no que diz respeito ao tratamento de dados pessoais e à livre circulação desses dados, lei $n^{\circ} 58$, publicada no diário da república, $1^{\text {a }}$ série, $\mathrm{n}^{\circ} 151$, pp. 3-38. 
Dolgoff, R., Loewenberg, F. M., \& Harrington, D. (2009). Ethical Decisions for Social Work Practic. Thomson Higher Education.

Frederic G. Reamer (2017) Evolving Ethical Standards in the Digital Age. Australian Social Work, 70:2, pp. 148-159, DOI: 10.1080/0312407X.2016.1146314 https://doi.org/10.1080/0312407X.2016.1146314

Frunză, S. (2011). Ethical responsibility and social responsibility of organizations involved in the public health system. Revista de Cercetare şi Intervenţie Socială, 32, 155-171.

George, J. (1999). Conceptual muddle, practical dilemma: Human rights, social development, and social work education. International Social Work, 42(1), 15-26.

Halabuza, D. (2014). Guidelines for Social Workers' Use of Social Networking Websites. Journal of Social Work Values \& Ethics, Spring 2014, Vol. 11, No. 1, 23-32.

Lambert, P. (2005). Secret professionnel. Bruylant.

Mattison, M. (2018). Informed Consent Agreements: Standards of Care for Digital Social Work Practices. Journal of Social Work Education, 54(2), 227-238.

McHale, J. (2003). Medical Confidentiality and Legal Privilege. Routledge.

Meersseman, C. (2019) La confidentialité, ciment de la relation d'aide:la personne au centre de la rencontre. In Donnet, A. et all (Ogs). Le secret professionnel,fondement de la relation d'aide et d'écoute. Fédération Wallonie.

Reamer, F. G. (2012). Essential Ethics Education in Social work Field Instruction. A Blueprint for Field Educators. The Field Educator: A Scholarly Journal from the Simmons College School of Social work. Volume 2.2/Fall 2012, 1-15.

Reamer, F. G. (2017). Evolving Ethical Standards in the Digital Age. Australian Social Work, Vol. 70 Issue 2, 148-159. https://doi.org/10.1080/0312407X.2016.1146314

Regulamento (UE) 2016/679 do Parlamento Europeu e do Conselho, de 27 de abril de 2016, relativo à proteção das pessoas singulares no que diz respeito ao tratamento de dados pessoais e à livre circulação desses dados e que revoga a Diretiva 95/46/CE (Regulamento Geral sobre a Proteção de Dados).

Resolução da Assembleia da República n. ${ }^{\circ}$ 1/2001 Aprova, para ratificação, a Convenção para a Proteção dos Direitos do Homem e da Dignidade do Ser Humano face às Aplicações da Biologia e da Medicina: Convenção sobre os Direitos do Homem e a Biomedicina, aberta à assinatura dos Estados membros do Conselho da Europa em Oviedo, em 4 de abril de 1997, e o Protocolo Adicional Que Pró́be a Clonagem de Seres Humanos, aberto à assinatura dos Estados membros em Paris, em 12/01/1998.

Sampaio, S. S.L., \& Rodrigues, F. W. (2014). Ética e sigilo profissional. Serviço Social \& Sociedade, (117), 84-93. https://doi.org/10.1590/S0101-66282014000100006

Sandu, A., \& Caras, A. (2013). Philosophical Practice and Social Welfare Counselling and Supervision of Ethics. Journal of the APPA Philosophical Practice, 8(3), 1287-1296.

Shaw, I.; Briar-Lawson, K.; Orme, J. \& Ruckdeschel, R. (2010). The Sage Handbook Social Work Research. Sage. 